\title{
The efficacy and safety of small incision open reduction and intramedullary nail fixation surgery in the treatment of simple tibial shaft fracture
}

chen shi ( $\square$ chenshi65536811@126.com )

ninghai first hospital https://orcid.org/0000-0003-1062-2682

he shan hai

Ninghai first hospital

zhang xiao lei

Ninghai first hospital

xu chun cheng

Ninghai first hospital

yang jian cheng

Ninghai first hospital

hong chuan

Ninghai first hospital

yu jia nan

Ninghai first hospital

Research article

Keywords: Closed reduction, small incision open reduction, simple tibial shaft fracture, intramedullary nail

Posted Date: October 5th, 2021

DOI: https://doi.org/10.21203/rs.3.rs-919258/v1

License: (c) (i) This work is licensed under a Creative Commons Attribution 4.0 International License.

Read Full License 


\section{Abstract}

Objective: To explore the clinical efficacy and safety of small incision open reduction and intramedullary nail internal fixation surgery in the treatment of simple tibial shaft fracture compared to the closed reduction surgery.

Methods: A total of fifty patients with simple tibial shaft fractures admitted to our hospital were randomly and equally assigned into the observation group and the control group. Patients in the observation group received small incision open reduction surgery with intramedullary nail while patients in the control group received the closed reduction surgery. The clinical efficacy, prognosis as well as safety profile were compared between the two groups.

Results: Our data indicated that the average bleeding volume of patients in the observation group was increased while the operation time was decreased compared to the control group. No significant difference of postoperative complications, fracture healing time, and Johner-Wruhs scores was identified between the two groups.

Conclusion: The small incision open reduction surgery can significantly shorten the operation time while achieved a similar clinical efficacy compared to the closed reduction surgery in simple tibial shaft fracture.

\section{References}

1. Larsen $P$, et al. Incidence and epidemiology of tibial shaft fractures. Injury. 2015;46(4):746-50.

2. Shaoting X, Baofeng G, Yinkan X. Practical Orthopedics. People's Military Medical Press; 2012.

3. Zhaojun S. Comparison of the effects of closed reduction and open reduction with interlocking intramedullary nail fixation in the treatment of tibiofibular shaft fractures. Medical frontiers. 2019;9(25):99.

4. Tejwani N, Polonet D, Wolinsky PR. Controversies in the intramedullary nailing of proximal and distal tibia fractures. J Am Acad Orthop Surg. 2014;22(10):665-73.

5. Zelle BA, Boni G. Safe surgical technique: intramedullary nail fixation of tibial shaft fractures. Patient Saf Surg. 2015;9:40.

6. Jun X, et al. Treatment of tibial shaft fractures with closed or limited open reduction and interlocking intramedullary nails. Journal of Practical Orthopedics. 2013;19(5):465-7.

7. Ricci WM, et al. Fractures of the proximal third of the tibial shaft treated with intramedullary nails and blocking screws. J Orthop Trauma. 2001;15(4):264-70.

8. Wei G, et al. Application of transsuprapatellar locking tibial intramedullary nail in the treatment of multi-segment tibial shaft fractures. Chinese Journal of Orthopaedics Traumatology. 2018;20(2):167-71. 
9. Daley-Lindo TS, et al. Long-Term Patient-Reported Knee Outcomes After Suprapatellar Intramedullary Tibial Nailing. Indian J Orthop. 2021;55(3):669-72.

10. Brink O. Suprapatellar nailing of tibial fractures: surgical hints. Curr Orthop Pract. 2016;27(1):10712.

11. Johner R, Wruhs O. Classification of Tibial Shaft Fractures and Correlation with Results after Rigid Internal Fixation. Clin Orthop Relat Res. 1983;178(178):7-25.

12. Lu K, et al., Semiextended approach for intramedullary nailing via a patellar eversion technique for tibial-shaft fractures: Evaluation of the patellofemoral joint. Injury, 2019.

13. Martus JE. Operative Fixation Versus Cast Immobilization: Tibial Shaft Fractures in Adolescents. J Pediatr Orthop. 2021;41(Suppl 1):S33-s38.

14. Scolaro JA, Broghammer FH, Donegan DJ. Intramedullary Tibial Nail Fixation of Simple Intraarticular Distal Tibia Fractures. J Orthop Trauma. 2016;30(Suppl 4):S12-6.

15. Guo $\mathrm{C}$, et al. Comparing intramedullary nailing and plate fixation for treating distal tibail fractures: $A$ meta-analysis of randomized controlled trials. Int J Surg. 2018;53:5-11.

16. Ebraheim NA, et al. Comparison of intramedullary nail, plate, and external fixation in the treatment of distal tibia nonunions. Int Orthop. 2017;41(9):1925-34.

17. Costa ML, et al. Effect of Locking Plate Fixation vs Intramedullary Nail Fixation on 6-Month Disability Among Adults With Displaced Fracture of the Distal Tibia: The UK FixDT Randomized Clinical Trial. JAMA. 2017;318(18):1767-76.

18. Beytemur $\mathrm{O}$, et al. Comparison of intramedullary nailing and minimal invasive plate osteosynthesis in the treatment of simple intra-articular fractures of the distal tibia (AO-OTA type 43 C1-C2). Acta Orthop Traumatol Turc. 2017;51(1):12-6.

19. Balbachevsky D, et al., Intramedullary nail versus bridge plate in open tibial fractures - randomized clinical trial. Injury, 2021.

20. Uemi R, et al. Early versus delayed weight bearing after intramedullary nailing for tibial shaft fracture: A multicenter, propensity score-matched study, the TRON study. Injury. 2021;52(6):1583-6.

21. Beebe MJ, et al. Extreme Nailing: Is It Safe to Allow Immediate Weightbearing After Intramedullary Nail Fixation of Extra-articular Distal Tibial Fractures (OTA/AO 43-A). J Orthop Trauma. 2019;33(8):392-6.

22. Duygun F, Aldemir C. Effect of intramedullary nail compression amount on the union process of tibial shaft fracture and the evaluation of this effect with a different parameter. Eklem Hastalik Cerrahisi. 2018;29(2):87-92.

23. Gaebler $C$, et al. Reamed versus minimally reamed nailing: a prospectively randomised study of 100 patients with closed fractures of the tibia. Injury. 2011;42(Suppl 4):S17-21.

24. McMahon SE, et al. The management of segmental tibial shaft fractures: A systematic review. Injury. 2016;47(3):568-73. 
25. Hu L, et al., Comparison of intramedullary nailing and plate fixation in distal tibial fractures with metaphyseal damage: a meta-analysis of randomized controlled trials. Journal of Orthopaedic Surgery and Research, 2019. 14(1).

26. Mukherjee $S$, et al. Interlocking Nailing Versus Plating in Tibial Shaft Fractures in Adults: A Comparative Study. J Clin Diagn Res. 2017;11(4):RC08-13.

27. Bhowmick K, Varghese VD. Retrograde Intramedullary Nailing for Recurrent Fracture in Congenital Pseudarthrosis of the Tibia. J Foot Ankle Surg. 2016;55(6):1287-91.

28. Bing $Y$, et al. Closed reduction and intramedullary nail internal fixation for the treatment of tibial shaft fractures. Chinese Journal of Bone Joint Injury. 2017;032(012):1308-9.

29. Yanjie W, Yabin L. Closed reduction expert intramedullary nail internal fixation for the treatment of middle and lower tibial fractures. Journal of Clinical Orthopedics. 2019;22(02):129.

30. Changhua T, et al., Small incision probe guided interlocking intramedullary nail internal fixation for the treatment of femoral and tibial shaft fractures. Chinese Journal of Bone and Joint Injury, 2013. 28(2).

31. Shen Juexin TW, Jinsheng C, Wenyu X, Baohua S, Comparison of open and closed reduction of tibial shaft fractures with intramedullary nail fixation. Chinese Journal of Bone and Joint Injury, 2011(Issue 7): p. 641-642.

32. Bishop JA, et al. Open reduction and intramedullary nail fixation of closed tibial fractures. Orthopedics. 2012;35(11):e1631-4.

33. Zhengxing Z, Yuejun Y. Analysis of the effect of limited open reduction and intramedullary nail fixation in the treatment of tibial fractures. Contemporary Medical Essays. 2016;14(09):150-1.

34. Rong $Y$, Guanghui W. The effect of limited open reduction and closed reduction with intramedullary nails in the treatment of tibial fractures. Jilin Medicine. 2014;35(004):726-7.

35. Tang $P$, et al. Does open reduction increase the chance of infection during intramedullary nailing of closed tibial shaft fractures? J Orthop Trauma. 2006;20(5):317-22.

36. Auston DA, et al. Percutaneous or Open Reduction of Closed Tibial Shaft Fractures During Intramedullary Nailing Does Not Increase Wound Complications, Infection or Nonunion Rates. J Orthop Trauma. 2017;31(4):215-9.

37. Magnusson EA, et al. Open Reduction of Closed Pediatric Tibial Shaft Fractures Treated With Intramedullary Stabilization Does Not Increase Risk of Postoperative Complications. J Orthop Trauma. 2020;34(9):482-7.

38. Albay C, Kaygusuz MA. Formulae derived from Anthropometric Measurements to Estimate Ideal Tibial Nail Length. Acta Ortop Bras. 2021;29(2):76-80.

39. Behlmer RJ, et al. Reduction techniques for intramedullary nailing of tibial shaft fractures: a comparative study. OTA Int. 2021;4(1):e095.

40. Orland MD, et al. Does Virtual Reality Improve Procedural Completion and Accuracy in an Intramedullary Tibial Nail Procedure? A Randomized Control Trial. Clin Orthop Relat Res. 
2020;478(9):2170-7.

41. Guo J, et al., Outcome Analysis of Intramedullary Nailing Augmented with Poller Screws for Treating Difficult Reduction Fractures of Femur and Tibia: a Retrospective Cohort Study. Biomed Res Int, 2021. 2021: p. 6615776.

42. Krettek $\mathrm{C}$, et al. The use of Poller screws as blocking screws in stabilising tibial fractures treated with small diameter intramedullary nails. J Bone Joint Surg Br. 1999;81(6):963-8.

43. Nork SE, et al. Intramedullary nailing of proximal quarter tibial fractures. J Orthop Trauma. 2006;20(8):523-8.

44. Archdeacon MT, Wyrick JD. Reduction plating for provisional fracture fixation. J Orthop Trauma. 2006;20(3):206-11.

45. Katsoulis E, Court-Brown C, Giannoudis PV. Incidence and aetiology of anterior knee pain after intramedullary nailing of the femur and tibia. J Bone Joint Surg Br. 2006;88(5):576-80.

46. Hernigou $P$, Cohen D. Proximal entry for intramedullary nailing of the tibia. The risk of unrecognised articular damage. J Bone Joint Surg Br. 2000;82(1):33-41.

47. Mochida H, Kikuchi S. Injury to infrapatellar branch of saphenous nerve in arthroscopic knee surgery. Clin Orthop Relat Res, 1995(320): p. 88-94.

48. Nyland $\mathrm{J}$, et al. Long-term quadriceps femoris functional deficits following intramedullary nailing of isolated tibial fractures. Int Orthop. 2001;24(6):342-6.

\section{Introduction}

Tibial fracture is a common type of fracture with an incidence of $16.9 / 100,000$ /year and accounts for approximately $13.7 \%$ of all fractures. Simple tibial shaft fractures (type A, B and C1, C2 in the AO classification) accounted for $34 \%$ of all tibial fractures[1,2]. The simple tibial shaft fracture mainly presents as calf pain, swelling, deformity and so on. In recent years, many studies [3-8] have shown that closed reduction or open reduction with intramedullary nail has a better efficacy compared to the conventional treatment method and can effectively shorten the fracture healing time as well as reduce the incidence of postoperative complications. However, these studies were mostly retrospective and included not only simple fractures, but also comminuted fractures, and Gustilo A, B, and C fractures. To further explore the clinical efficacy of closed or limited open reduction surgery and internal fixation with intramedullary nails for the treatment of simple tibial shaft fractures, we conducted a prospective study including 50 cases patients. The research results were reported as follows:

\section{Materials And Methods}

\subsection{Inclusion and exclusion criteria}

Inclusion criteria: 1. Patients with simple tibial shaft fractures (Type A, B and C1, C2 according to the AO classification); 2 . No open wound discovered around the fracture area; 3 . No significant ipsilateral 
displacement that affecting reduction of ankle and knee fractures; 4 . Normal cardiopulmonary function and stable hemodynamics; 5 . No obvious osteoporosis;

Exclusion criteria: 1. Patients with complex, comminuted or multi-segment tibial shaft fracture; 2. Complicated with open injury involved the operation area; 3. Ipsilateral knee and ankle joint injury and/or fracture displacement that affecting the operation method; 4 . Patients with refractory severe hypertension $(>180 / 110 \mathrm{mmHg})$; patients with refractory blood sugar> 13.9mmol/L; patients with severe cardiopulmonary, liver and kidney insufficiency; patients with systemic diseases and immunodeficiency; patients with severe malnutrition or conditions unsuitable for surgery; patients with infection, bacteremia, and/or sepsis; other conditions which might render the patient intolerable for surgery; 5 . patients with severe osteoporosis that affect the stability of intramedullary nail fixation; 6 . patients who refused to participate the study; 7 . Patients with severe mental illness or other cognitive disorders that might seriously affect postoperative functional evaluation; 8. Patients with pathological fractures;

\subsection{Surgical procedures}

All patients were operated on by the same experienced orthopedic and trauma surgeon. To prevent biases, all records were examined by two independent orthopedic surgeons who had no relation with the patient $\$ s treatment.

All patients were in the supine position and received spinal anesthesia. All intramedullary nails were nonreamed locking tibial interlocking intramedullary nail system (CanTN) provided by CANWELL.

In this study, all surgeries used infrapatellar approach. Some other studies $[9,10]$ might argue that the suprapatellar approach was a better approach but this study was not powered to examine the difference between different approaches.

The observation group (small incision reduction intramedullary nail fixation method): Centered by the end of the fracture, a small incision, usually $3 \mathrm{~cm}$, was made with limited stripping of the periosteum before reducing the fracture end and temporarily fixing with bone clamp. Another longitudinal incision about $5 \mathrm{~cm}$ above the tibial tubercle was carried out and the patellar ligament was split longitudinally to expose the "slope" of the tibial plateau. The medial side of the intercondylar crest of the tibial plateau was used as the entry point, and the platform was opened to the medullary cavity with a triangular pyramidal. Then the guide pin was inserted into the medullary cavity, followed by the selected intramedullary nail along the guide pin under $\mathrm{C}$-arm fluoroscopy. After inserting the intramedullary nail, the temporarily fixed bone clamp was removed and the remote locking nail was installed followed by 2 suitable locking nails through the sleeve of the remote sight. Draw with the intramedullary nail backwards, and appropriately pressurize the fracture area. Insert 2 or 3 proximal locking nails through the sleeve of the proximal sight and remove the bracket and screw in the tail cap before the completion of the surgery.

The control group (closed reduction intramedullary nail fixation ): The closed reduction operation was used to reduce the fracture end, and the intramedullary nail was inserted after C-arm fluoroscopy 
identified the ideal position of the fracture end. The rest of the operation was carried out the same as the observation group.

\subsection{Postoperative management}

One day after the operation, antibiotics was given to prevent infection as well as other supportive treatments to relieve pain and other symptoms. On the second day after the operation, active flexion and extension exercises of knee joint, ankle joint and toe were performed in bed. After clinical and X-ray examinations showing clinical healing of the fracture, crutches can be gradually abandoned. Series of imaging were regularly taken to monitor the fracture healing process.

\subsection{Observation indicators:}

The operation time, blood loss and intraoperative complications (such as whether there is blood vessel or nerve damage) were documented. Patient was followed up at 2 weeks, 1 month, 3month and 6 months after the operation by either on-site or telephone follow-up. At two weeks and one month after the operation, the local incision healing of the patients was evaluated as well as the presence or absence of postoperative incision infection. The fracture healing and the function of the affected limb were observed at 1 month, 3month and 6 months after the operation (according to the Johner-Wruhs scoring standard[11] and was graded into four levels: excellent, good, moderate, and poor).

\subsection{Statistical methods:}

All data was processed by statistical software SPSS12.0. The comparison between groups was examined by $t$ test and $\chi 2$ test. $P<0.05$ indicated that the difference was statistically significant.

\subsection{Safety indicators:}

The two surgical methods applied in the study were verified for safety and the surgical technology was mature. In the process of closed reduction of the fracture end, the posterior tibial blood vessels and nerves might be damaged when the bone clamp was applied, but the incidence was extremely low. In this experiment, 3 patients with vascular and nerve damage were selected for safety indicators. If the adverse event exceeded the predetermined index, the experiment would be immediately terminated.

This study complies with relevant ethical standards and was approved by the hospital ethics committee.

\section{Results}

\subsection{Study population}

A total of 50 patients with simple tibial fracture diagnosed at our hospital from 2019 to 2020 were prospectively enrolled in this study. All patients signed informed consent forms and were randomly and equally divided into the observation group and the control group. In the observation group, there were 19 male patients and 6 female patients ranged from 27 to 63 years, with an average age of $(43.28 \pm 2.62)$ years and consisting of 9 type $A, 11$ type $B$, and 5 type $C$ fractures. In the control group, there were 17 
male patients and 8 female patients ranged from 25 to 63 years old, with an average age of $(43.88 \pm 2.32)$ years and consisting of 10 type $A, 12$ type $B$, and 3 type $C$ fractures. No significant difference was observed in the baseline characteristics between two groups.

\subsection{Operation time, blood loss and fracture healing time}

In this group, the average operation time of the observation group was $(56.12 \pm 1.392 \mathrm{~min})$, the average operation time of the control group was $(76.84 \pm 1.827 \mathrm{~min})$; the average blood loss of the observation group was $(72.88 \pm 2.938 \mathrm{ml})$, and the average blood loss of the control group was $(56.16 \pm 2.306 \mathrm{ml})$. The fracture healing time of the observation group was (162.0 \pm 7.425$)$ days, and the healing time of the control group was (158.8 \pm 8.770$)$ days. (See Figure 1 for details)

As shown in table 1, the average operation time was significantly decreased in the observation group compared to the control group (56.12 $\pm 1.392 \mathrm{~min}$ vs $76.84 \pm 1.827 \mathrm{~min}, \mathrm{P} \otimes 0.05)$. Meanwhile, the average blood loss in the observation group was significantly increased compared to the control group ( $72.88 \pm 2.938 \mathrm{ml}$ vs $56.16 \pm 2.306 \mathrm{ml}, \mathrm{P} \otimes 0.05)$. However, the implicit bleeding was not counted in the control group. Furthermore, no significant difference of postoperative complications and fracture healing time was observed between groups ( $P>0.05)$. (See Table 1 for details)

Table 1 Comparison of various indicators between the small incision open reduction group and the closed reduction group $₫ \times \pm s \rrbracket$

\begin{tabular}{|c|c|c|c|c|}
\hline & Number & Surgery time $₫ \min \rrbracket$ & Blood $\triangle \mathrm{ml} \otimes$ & 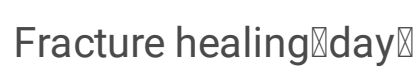 \\
\hline Observation group & 25 & $56.12 \pm 1.392$ & $72.88 \pm 2.938$ & $162.0 \pm 7.425$ \\
\hline Control group & 25 & $76.84 \pm 1.827$ & $56.16 \pm 2.306$ & $158.8 \pm 8.770$ \\
\hline$P$ value & 0.8647 & $₫ 0.0001^{*}$ & $\varangle 0.0001^{*}$ & 0.7845 \\
\hline
\end{tabular}

\subsection{Complications}

One patient in the observation group experienced redness and swelling of the incision at the fracture end with limited exudation. Local infection was considered and successfully treated with prolonged antibiotic use and wound dressing. One patient in the control group developed local skin redness and swelling at the knee joint and was recovered after repeated wound dressing. No serious infection was identified in both groups.

All patients received small incision open reduction surgery achieved, or at least close to, anatomical reduction at the fracture. While all patients in the closed reduction group had a good reduction of the fracture end with alignment accuracy exceeded $80 \%$ and limited limb shortening (within $1 \mathrm{~cm}$ ). In addition, no one in the observation group developed internal rotation in the ankle joint and the external rotations were all within $10^{\circ}$. 
One patient in the observation group and one in the control group had delayed union of the fracture end after the operation.

A total of 5 patients in the observation group and 4 in the control group complained pain in the knee area after surgery, mainly in the deep part of the anterior knee incision.

\subsection{Postoperative function}

According to the Johner-Wruhs scoring standard, 18 patients in the observation group fall into the excellent category while 6 in good and 1 in fair categories resulting a $96 \%$ rate in achieving good or beyond postoperative function. On the other hand, 18 patients in the control group fall into the excellent category while 5 in good and 2 in fair categories, resulting a 92\% rate in achieving good or beyond postoperative function. No significant difference was observed in term of postoperative function (P凶0.05).

Table 2 Comparison of postoperative complications and excellent rate of small incision open reduction group and closed reduction group

\begin{tabular}{|c|c|c|c|c|}
\hline V & $\begin{array}{l}\text { Delay } \\
\text { healing彵 }\end{array}$ & $\begin{array}{l}\text { Poor incision } \\
\text { healing }\end{array}$ & $\begin{array}{l}\text { Knee } \\
\text { pain } \otimes \square\end{array}$ & $\begin{array}{l}\text { The excellent and good rate of } \\
\text { Johner-Wruhs } \varangle \% \square\end{array}$ \\
\hline
\end{tabular}

प्राप

\begin{tabular}{lcllll}
$\begin{array}{l}\text { Observation } \\
\text { group }\end{array}$ & 25 & 1 & 1 & 5 & 96 \\
\hline $\begin{array}{l}\text { Control } \\
\text { group }\end{array}$ & 25 & 0 & 0 & 4 & 92 \\
\hline $\begin{array}{l}\text { P values } \\
\text { value }\end{array}$ & - & $>0.9999$ & $>0.9999$ & $>0.9999$ & $>0.9999$
\end{tabular}



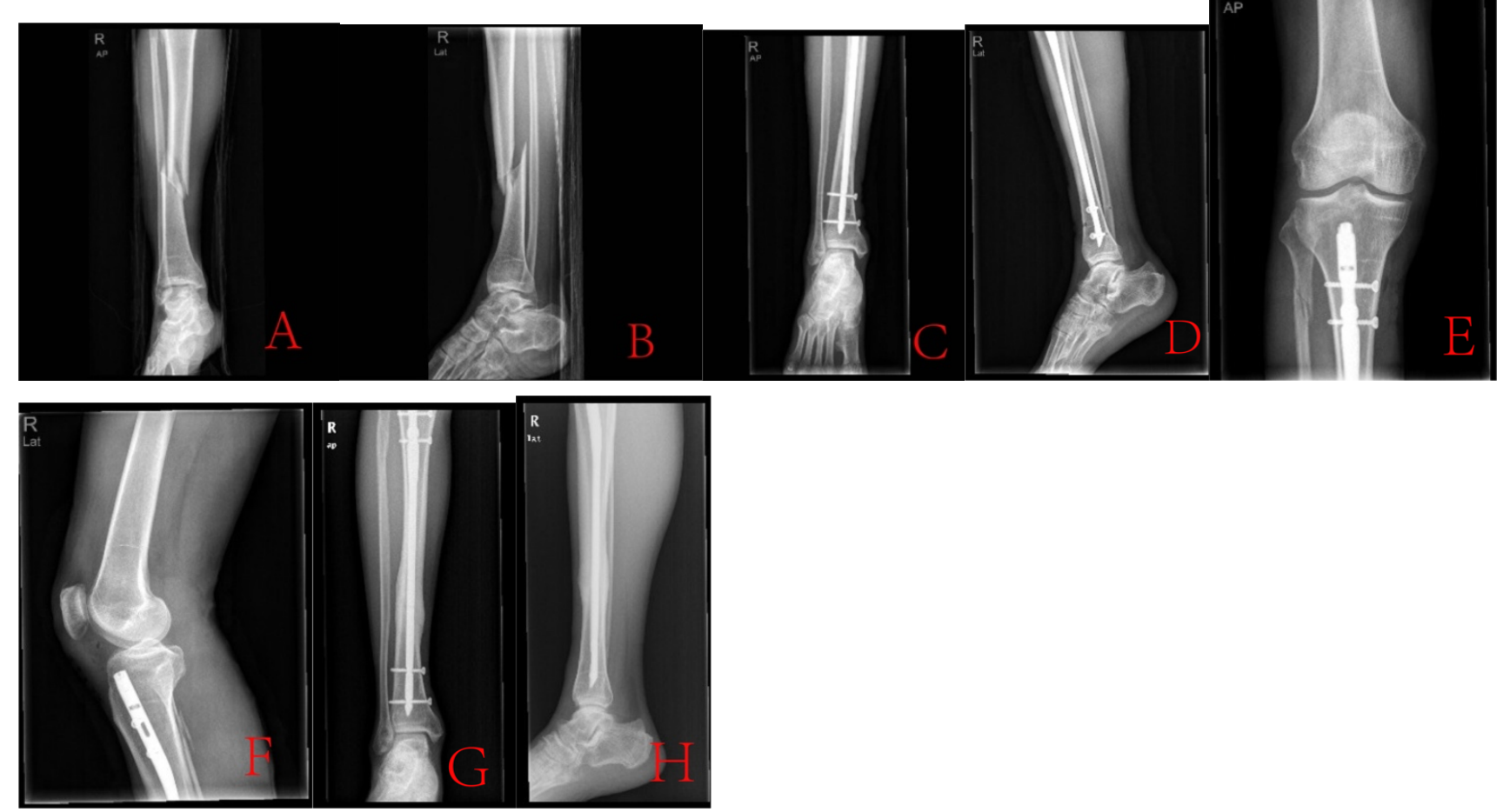

Case 1: A 55-year-old male who had a fracture in the middle and lower segment of right tibia. A-B, preoperative $\mathrm{X}$-ray: short spiral fracture in the middle of the tibia with dislocation of the fracture end; C-F, open reduction with a small incision, and internal fixation with intramedullary nails. Postoperative $\mathrm{X}$-ray indicated anatomical reduction of the fractured end; $\mathrm{G}-\mathrm{H}, 1$ year after operation, follow-up X-ray indicated good fracture healing;
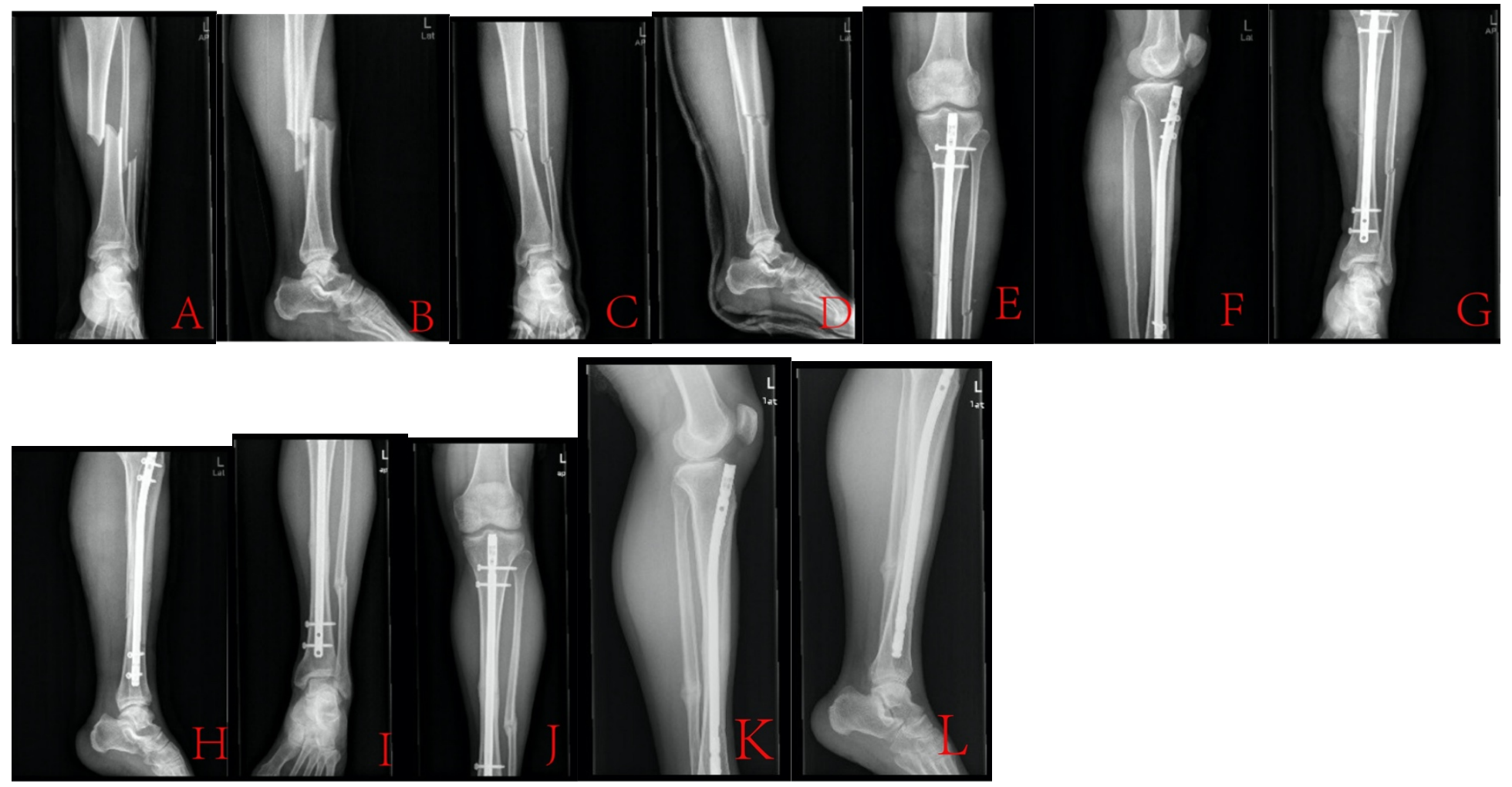
Case 2:A Case 2: 50-year-old male with left calf pain, deformity, and limited movement. A-B, after admission, emergency $\mathrm{X}$-ray revealed transverse fracture of the left tibia and fibula in the middle section, with significant displacement of the fracture end. C-D emergency orthopedic surgeon performed closed reduction and cast fixation. X-ray revealed a slight displacement of the fracture end. E-H, "closed reduction and internal fixation with intramedullary nail", the fibula was not treated. Postoperative $X$ - ray showed good alignment and anatomical condition. I-L, 1 year after surgery, follow-up X-ray showed good fracture healing;
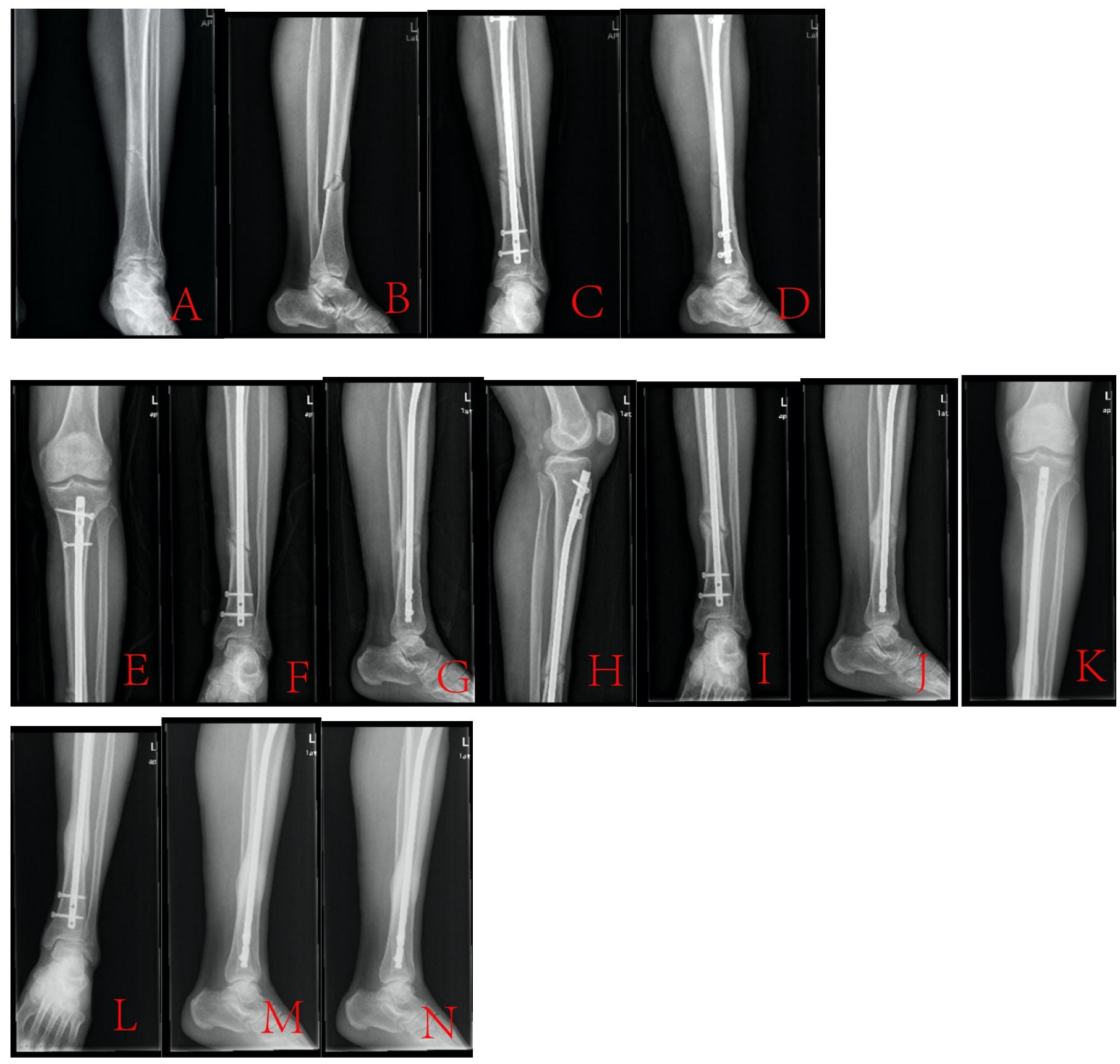

Case 3: 60-year-old male with fracture of the middle and lower segment in left tibia . A-B Preoperative Xray revealed slight displacement of the fracture; C-D performed "closed reduction and internal fixation with intramedullary nail"; E-H Three months after surgery, follow-up X-ray showed that the fracture end 
healing was not optimal. I-J, Four months after surgery, x-rays suggested delayed union of the fracture. The two proximal screws were removed, and the leg was stabilized on the ground followed by dynamic procedures. K-N Follow-up 1 year after surgery ,X-ray suggested fracture union.



Case 4: 46-year-old male with right mid-tibia fracture, right fibula microcephaly fracture, and right posterior ankle fracture. $A-B$, spiral fracture of the middle and lower segment tibia, displacement of the fracture end; C-E, "small incision open reduction and internal fixation with intramedullary nail" was performed. Free bone was discovered during the operation. In order to increase the stability of the local fracture end, a locking bone plate was placed to strengthen the fixation. The posterior malleolus fracture was in a good position. One screw was inserted to fix the posterior malleolus fracture. Postoperative $X$ ray revealed anatomic reduction of fracture. F-G, 6 months postoperative follow-up X-ray showed good fracture healing;

\section{Discussion}

The goal of surgical treatment for simple tibial fracture is to achieve bone healing and restore the length, alignment, and rotation of tibial. There are various fracture treatment methods and for fractures with unstable and displaced fractures, early internal fixation has become the first line of choice for many clinicians[12, 13] $[$ The conventional plate fixation requires a long surgical incision with nonavoidable soft tissue and periosteum peeling which often result in prolonged healing and increased risk for infection. In addition, the stability of external fixation stent is relatively weak and the nail tract infection and loosening may occur.

It is considered that for patients with severe open tissue injury, only short-term fixation can be used. The axial fixation of the interlocking intramedullary nail is stable and can conduct physiological stress. After the intramedullary nail is implanted, the surrounding bone tissue is compressed to form an elastic fixation between the nail and the bone. At the same time, this procedure does not damage the blood supply in the fracture end [14-19] and help to accelerate the healing process[20, 21]. This method becomes especially important for severe comminuted fractures due to its incomparable advantages over steel plates[16, 18 , 22-25] . Due to the above merits, interlocking intramedullary nails have become the first-line treatment for unstable tibial fractures[26, 27]. 
However, when intramedullary nails are used for internal fixation, there is still a clinical controversy regarding the reduction of fracture ends[18]. Some scholars believe that the blood supply of the tibia come from the nourishing arteries and periosteal vessels. When the nourishing arteries are destroyed after the tibial shaft fractures, the periosteum associated vessels gradually become the main source of blood supply. The open reduction surgery often result in periosteal dissection, especially for patients with severe comminuted fractures, which will seriously affect the blood supply of the affected limb and increase the difficulty of postoperative healing. However, the closed reduction intramedullary nail internal fixation does not need to expose the fracture end therefore preserve the integrity of periosteum and reduce surgeryrelated complications [28-30].

However, some other physicians [6, 18, 30-34] prefer small incision limited open reduction and intramedullary nail internal fixation for its advantage to achieve anatomical reduction and reduced operation time. Considering the fact that limited incision and proper periosteal dissection may help to preserve the blood supply of the fracture end, this method may not associate with many serious adverse events during the healing process of the fracture.

This study suggested that the small incision surgery can achieve anatomical reduction and effectively reduced the operation time compared to the closed reduction surgery. In terms of fracture healing time and postoperative function, no significant difference was discovered between two groups. Although the amount of bleeding was slightly increased in the incision surgery group (occult bleeding was not considered), it was not associated with any serious adverse event during the perioperative period.

Although both surgical methods can achieve good clinical results, patients in the observation group still have poor incision healing and delayed fracture healing. And,both groups of patients had anterior knee pain. In this regard, the author's experience is:

\subsection{Infection}

Previous studies have suggested [35-37] that multiple incisions were associated with a trend of increasing risk of infection. However, our data suggested only one patient in the small incision group showed infection like symptoms such as local skin redness and exudation at the incision cite, which were improved after prolonged antibiotics treatment. Beside surgery technique, many other factors such as timing of the operation, local skin condition, and the patient's general condition can contribute to the occurrence of infection. For patients with poor soft tissue condition at the fracture end, open reduction should be carried out with extra cautious. The treatment of soft tissue injury is as important as the treatment of the fracture itself. Any choice of treatment should try to avoid further aggravating the soft tissue injury. In general, small local incisions infection may occur but rarely develop into systemic infection if operation protocol was strictly followed.

\subsection{Bone healing}

Judgment criteria for fracture healing mainly include three components: 3 or more cortical callus bridging on X-ray film, no tenderness at the fracture site and axial percussion pain. Studies have shown 
$[35,37]$ that open reduction surgery did not increase the risk of bone nonunion. The results of this study showed that there was no bone nonunion identified in either group.

The author's experience is that a variety of measures can effectively prevent nonunion or delayed union of fractures:

3.2.1 Protect the blood supply of the fractured end:There are some tips in small incision open reduction surgery that worth noticing: try not to or minimize the strip of the periosteum during the operation; after reduction, a bone clamp should be used to temporarily fix the fracture site to prevent the fracture end from shifting. It should be noted that when using percutaneous forceps, the point clamp should be kept close to the bone surface and gently manipulated, otherwise the posterior tibial blood vessels and nerves might be damaged.

3.2.2 Length selection of intramedullary nail: An appropriate length of intramedullary nail $[10,38]$ can effectively increase the stability of the fracture end and promote an eventless recovery.

\subsubsection{Increases stability of the fracture end}

\Appropriate compression of the fracture end: Duygun, $F[22]$ et al.'s suggested that for tibial shaft fractures, moderate compression of the fracture end by intramedullary nails effectively promoted fracture healing. Based on the same study, the proper compression of the fracture end reduced the fracture gap and shortened the space for the callus bridging, which both beneficial to the primary healing of the fracture. In the small incision reduction group, one patient experienced a delayed healing (case 3), which was improved after removing the proximal lock.

पAuxiliary plate or blocking nail technology:The study of Behlmer, R.J [39-41] et al. suggested that the application of various reduction techniques such as traction, percutaneous reduction clamp technique and blocking nail technique, can help fracture reduction and reduce intraoperative complications. The blocking nail technique can be considered if poor restoration persisted[7, 42].

After inserting the intramedullary nail, a locking plate can be used if the fracture end was unstable [43, 44]. In the small incision reduction group $₫$ case $4 \bigotimes$, after the intramedullary nail was inserted, the stability of the fractured end was poor, and a auxiliary plate was used, which help the fracture end to heal sucsuccessful. But it should be noted that \the soft tissue between the bone should be carefully removed during the operation to promote the primary healing of the fracture.

\subsection{Anterior knee pain}

Previous study suggested [45] that the incidence of anterior knee pain after tibial intramedullary nailing was $47 \%$. The specific cause of anterior knee pain is unknown which may be related to iatrogenic injury during intramedullary nail insertion, injury to the subpatellar branch of the saphenous nerve, quadriceps and other related neuromuscular reflex inhibition, subpatellar fat pad fibrosis, reactive patella tendinitis, excessive nail tail irritation, local low-toxicity infection, long-term weight-bearing osteoporosis, and proximal intramedullary nail protrusion[45-48]. The results of this study showed that a total of 5 patients 
in the observation group and 4 patients in the control group complained of knee joint pain after surgery. The pain was mainly localized to the front of their knees and can be improved after symptomatic treatment such as pain relief and functional exercise. Extra attention should be paid to avoid damage to the patellar tendon and subpatellar fat pad during the operation and to select the entry point. Furthermore, repeated insertion and removal of the intramedullary nail should be avoided and rehabilitation exercises should be promoted as early as possible. All above measures can effectively reduce the incidence of anterior knee pain based on our experience. For elderly patients or patients with osteoporosis tendency, timely anti-osteoporosis treatment should be considered.

Highlights of this study: 1 . All patients included in this study were diagnosed with simple tibial shaft fractures and prospectively followed-up; 2 . All patients received the same specification Intramedullary nails, the same surgical approach and surgical methods;

The limits of this study: 1 . This study only enrolled patients with simple tibial fracture and whether the small incision reduction surgery can be used in more complicated situation (Type $\mathrm{C} 3$ according to the $\mathrm{AO}$ classification)need to be further examined; 2 . Only non-reamed intramedullary nails were used in this study and the efficacy and safety of reamed intramedullary remained to be further studied; 3 . This was a single-center prospective study, which might not be representable for the general population ; 4 . The number of patients enrolled in this study was relatively small.

In summary, small incision surgery can decrease operation time and achieve a similar efficacy and safety profile compared to the close reduction surgery in simple tibial fracture.

\section{Declarations}

Ethics approval and consent to participate

Consent for publication

Availability of data and materials

Approved by the hospital ethics committee

Page 15/21 
Research Registration Unique Identifying Number (UIN)

1. Name of the registry: Chinese clinical trial registry

2. Unique Identifying number or registration ID: ChiCTR2100051290

Competing interests

We declare no conflict of interest.

Funding

This research was not supported by relevant funds

Authors' contributions

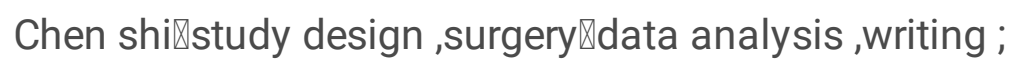

He shan hai [Zhang xiao lei:surgery

Xu chun cheng $\square$ Yang jian cheng $\square$ Hong chuang $\square$ Yu jia nan: data collection ,data analysis ;

\section{Guarantor}

We promise to control the whole process of this study, including research design $\llbracket$ surgery $\llbracket$ data collection $a$ analysis and paper writing. It will be objective and accurate, no fraud or plagiarism, and We will be responsible for this study.

\section{References}

1. Larsen, P., et al., Incidence and epidemiology of tibial shaft fractures. Injury, 2015. 46(4): p. 746-50. 
2. Shaoting, X., G. Baofeng, and X. Yinkan, Practical Orthopedics. People's Military Medical Press, 2012.

3. Zhaojun, S., Comparison of the effects of closed reduction and open reduction with interlocking intramedullary nail fixation in the treatment of tibiofibular shaft fractures. Medical frontiers, 2019. 9(25): p. 99.

4. Tejwani, N., D. Polonet, and P.R. Wolinsky, Controversies in the intramedullary nailing of proximal and distal tibia fractures. J Am Acad Orthop Surg, 2014. 22(10): p. 665-73.

5. Zelle, B.A. and G. Boni, Safe surgical technique: intramedullary nail fixation of tibial shaft fractures. Patient Saf Surg, 2015. 9: p. 40.

6. Jun, X., et al., Treatment of tibial shaft fractures with closed or limited open reduction and interlocking intramedullary nails. Journal of Practical Orthopedics, 2013. 19(5): p. 465-467.

7. Ricci, W.M., et al., Fractures of the proximal third of the tibial shaft treated with intramedullary nails and blocking screws. J Orthop Trauma, 2001. 15(4): p. 264-70.

8. Wei, G., et al., Application of transsuprapatellar locking tibial intramedullary nail in the treatment of multi-segment tibial shaft fractures. Chinese Journal of Orthopaedics and Traumatology, 2018. 20(2): p. 167-171.

9. Daley-Lindo, T.S., et al., Long-Term Patient-Reported Knee Outcomes After Suprapatellar Intramedullary Tibial Nailing. Indian J Orthop, 2021. 55(3): p. 669-672.

10. Brink, O., Suprapatellar nailing of tibial fractures: surgical hints. Curr Orthop Pract, 2016. 27(1): p. 107112.

11. Johner, R. and O. Wruhs, Classification of Tibial Shaft Fractures and Correlation with Results after Rigid Internal Fixation. Clinical Orthopaedics and Related Research, 1983. 178(178): p. 7-25.

12. Lu, K., et al., Semiextended approach for intramedullary nailing via a patellar eversion technique for tibial-shaft fractures: Evaluation of the patellofemoral joint. Injury, 2019.

13. Martus, J.E., Operative Fixation Versus Cast Immobilization: Tibial Shaft Fractures in Adolescents. J Pediatr Orthop, 2021. 41(Suppl 1): p. S33-s38.

14. Scolaro, J.A., F.H. Broghammer, and D.J. Donegan, Intramedullary Tibial Nail Fixation of Simple Intraarticular Distal Tibia Fractures. J Orthop Trauma, 2016. 30 Suppl 4: p. S12-S16.

15. Guo, C., et al., Comparing intramedullary nailing and plate fixation for treating distal tibail fractures: $A$ meta-analysis of randomized controlled trials. Int J Surg, 2018. 53: p. 5-11.

16. Ebraheim, N.A., et al., Comparison of intramedullary nail, plate, and external fixation in the treatment of distal tibia nonunions. Int Orthop, 2017. 41(9): p. 1925-1934. 
17. Costa, M.L., et al., Effect of Locking Plate Fixation vs Intramedullary Nail Fixation on 6-Month Disability Among Adults With Displaced Fracture of the Distal Tibia: The UK FixDT Randomized Clinical Trial. JAMA, 2017. 318(18): p. 1767-1776.

18. Beytemur, O., et al., Comparison of intramedullary nailing and minimal invasive plate osteosynthesis in the treatment of simple intra-articular fractures of the distal tibia (AO-OTA type 43 C1-C2). Acta Orthop Traumatol Turc, 2017. 51(1): p. 12-16.

19. Balbachevsky, D., et al., Intramedullary nail versus bridge plate in open tibial fractures - randomized clinical trial. Injury, 2021.

20. Uemi, R., et al., Early versus delayed weight bearing after intramedullary nailing for tibial shaft fracture: A multicenter, propensity score-matched study, the TRON study. Injury, 2021. 52(6): p. 1583-1586.

21. Beebe, M.J., et al., Extreme Nailing: Is It Safe to Allow Immediate Weightbearing After Intramedullary Nail Fixation of Extra-articular Distal Tibial Fractures (OTA/AO 43-A)? J Orthop Trauma, 2019. 33(8): p. 392-396.

22. Duygun, F. and C. Aldemir, Effect of intramedullary nail compression amount on the union process of tibial shaft fracture and the evaluation of this effect with a different parameter. Eklem Hastalik Cerrahisi, 2018. 29(2): p. 87-92.

23. Gaebler, C., et al., Reamed versus minimally reamed nailing: a prospectively randomised study of 100 patients with closed fractures of the tibia. Injury, 2011. 42 Suppl 4: p. S17-21.

24. McMahon, S.E., et al., The management of segmental tibial shaft fractures: A systematic review. Injury, 2016. 47(3): p. 568-73.

25. Hu, L., et al., Comparison of intramedullary nailing and plate fixation in distal tibial fractures with metaphyseal damage: a meta-analysis of randomized controlled trials. Journal of Orthopaedic Surgery and Research, 2019. 14(1).

26. Mukherjee, S., et al., Interlocking Nailing Versus Plating in Tibial Shaft Fractures in Adults: A Comparative Study. J Clin Diagn Res, 2017. 11(4): p. RC08-RC13.

27. Bhowmick, K. and V.D. Varghese, Retrograde Intramedullary Nailing for Recurrent Fracture in Congenital Pseudarthrosis of the Tibia. J Foot Ankle Surg, 2016. 55(6): p. 1287-1291.

28. Bing, Y., et al., Closed reduction and intramedullary nail internal fixation for the treatment of tibial shaft fractures. Chinese Journal of Bone and Joint Injury, 2017. 032(012): p. 1308-1309.

29. Yanjie, W. and L. Yabin, Closed reduction expert intramedullary nail internal fixation for the treatment of middle and lower tibial fractures. Journal of Clinical Orthopedics, 2019. 22(02): p. 129. 
30. Changhua, T., et al., Small incision probe guided interlocking intramedullary nail internal fixation for the treatment of femoral and tibial shaft fractures. Chinese Journal of Bone and Joint Injury, 2013. 28(2).

31. Shen Juexin, T.W., Chen Jinsheng, Xiao Wenyu, Shi Baohua, , Comparison of open and closed reduction of tibial shaft fractures with intramedullary nail fixation. Chinese Journal of Bone and Joint Injury, 2011(Issue 7): p. 641-642.

32. Bishop, J.A., et al., Open reduction and intramedullary nail fixation of closed tibial fractures. Orthopedics, 2012. 35(11): p. e1631-4.

33. Zhengxing, Z. and Y. Yuejun, Analysis of the effect of limited open reduction and intramedullary nail fixation in the treatment of tibial fractures. Contemporary Medical Essays, 2016. 14(09): p. 150-151.

34. Rong, Y. and W. Guanghui, The effect of limited open reduction and closed reduction with intramedullary nails in the treatment of tibial fractures. Jilin Medicine, 2014. 35(004): p. 726-727.

35. Tang, P., et al., Does open reduction increase the chance of infection during intramedullary nailing of closed tibial shaft fractures? J Orthop Trauma, 2006. 20(5): p. 317-22.

36. Auston, D.A., et al., Percutaneous or Open Reduction of Closed Tibial Shaft Fractures During Intramedullary Nailing Does Not Increase Wound Complications, Infection or Nonunion Rates. J Orthop Trauma, 2017. 31(4): p. 215-219.

37. Magnusson, E.A., et al., Open Reduction of Closed Pediatric Tibial Shaft Fractures Treated With Intramedullary Stabilization Does Not Increase Risk of Postoperative Complications. J Orthop Trauma, 2020. 34(9): p. 482-487.

38. Albay, C. and M.A. Kaygusuz, Formulae derived from Anthropometric Measurements to Estimate Ideal Tibial Nail Length. Acta Ortop Bras, 2021. 29(2): p. 76-80.

39. Behlmer, R.J., et al., Reduction techniques for intramedullary nailing of tibial shaft fractures: a comparative study. OTA Int, 2021. 4(1): p. e095.

40. Orland, M.D., et al., Does Virtual Reality Improve Procedural Completion and Accuracy in an Intramedullary Tibial Nail Procedure? A Randomized Control Trial. Clin Orthop Relat Res, 2020. 478(9): p. 2170-2177.

41. Guo, J., et al., Outcome Analysis of Intramedullary Nailing Augmented with Poller Screws for Treating Difficult Reduction Fractures of Femur and Tibia: a Retrospective Cohort Study. Biomed Res Int, 2021. 2021: p. 6615776.

42. Krettek, C., et al., The use of Poller screws as blocking screws in stabilising tibial fractures treated with small diameter intramedullary nails. J Bone Joint Surg Br, 1999. 81(6): p. 963-8. 
43. Nork, S.E., et al., Intramedullary nailing of proximal quarter tibial fractures. J Orthop Trauma, 2006. 20(8): p. 523-8.

44. Archdeacon, M.T. and J.D. Wyrick, Reduction plating for provisional fracture fixation. J Orthop Trauma, 2006. 20(3): p. 206-11.

45. Katsoulis, E., C. Court-Brown, and P.V. Giannoudis, Incidence and aetiology of anterior knee pain after intramedullary nailing of the femur and tibia. J Bone Joint Surg Br, 2006. 88(5): p. 576-80.

46. Hernigou, P. and D. Cohen, Proximal entry for intramedullary nailing of the tibia. The risk of unrecognised articular damage. J Bone Joint Surg Br, 2000. 82(1): p. 33-41.

47. Mochida, H. and S. Kikuchi, Injury to infrapatellar branch of saphenous nerve in arthroscopic knee surgery. Clin Orthop Relat Res, 1995(320): p. 88-94.

48. Nyland, J., et al., Long-term quadriceps femoris functional deficits following intramedullary nailing of isolated tibial fractures. Int Orthop, 2001. 24(6): p. 342-6.

\section{Figures}




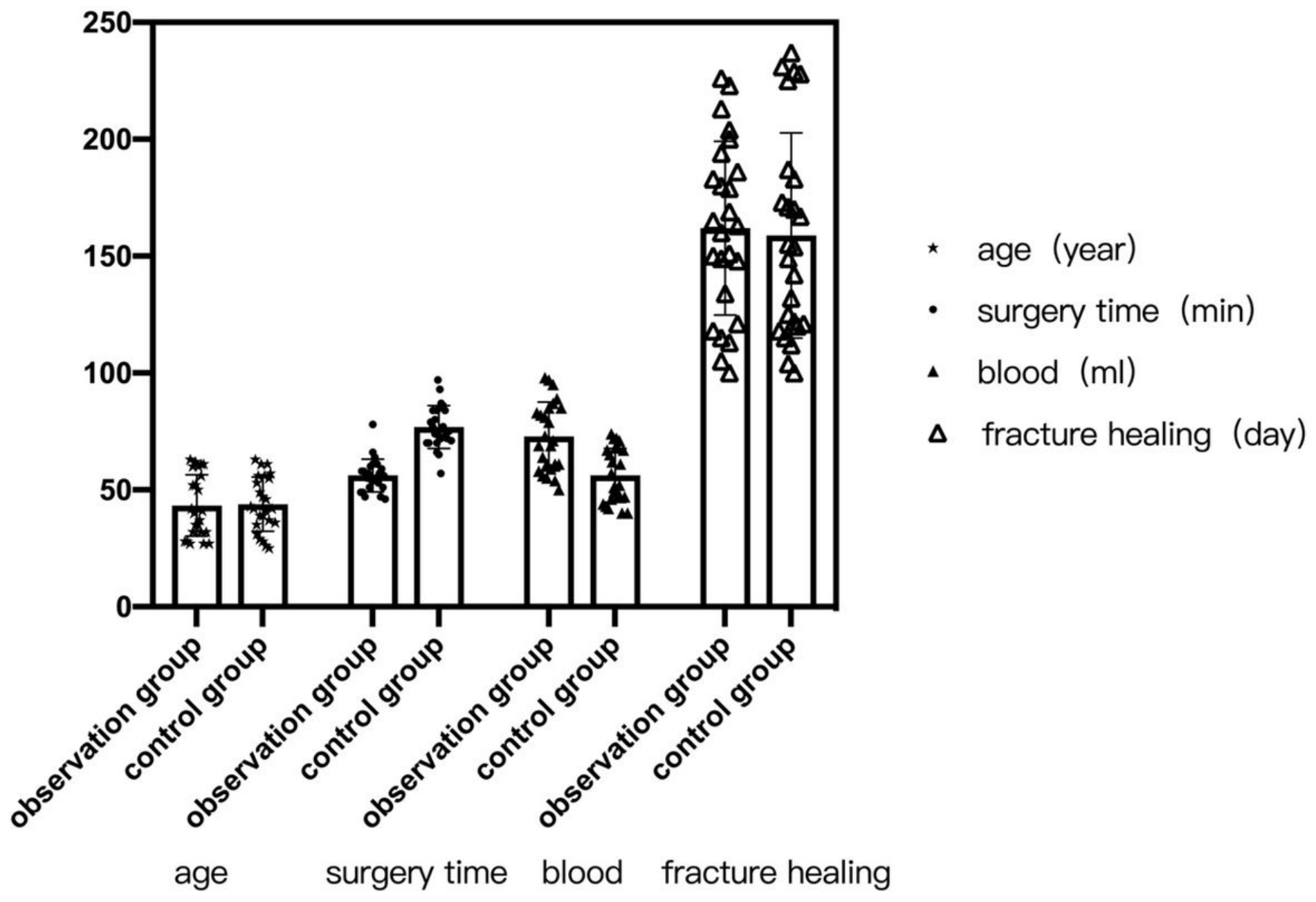

Figure 1

Comparison of various indicators between the small incision open reduction group and the closed reduction group 